\title{
Randomized pharmacokinetic evaluation of different rifabutin doses in African HIV- infected tuberculosis patients on lopinavir/ritonavir-based antiretroviral therapy
}

Suhashni Naiker ${ }^{1}$, Cathy Connolly ${ }^{2}$, Lubbe Wiesner ${ }^{3}$, Tracey Kellerman ${ }^{3}$, Tarylee Reddy ${ }^{2}$, Anthony Harries ${ }^{4}$, Helen Mcllleron ${ }^{3}$, Christian Lienhardt ${ }^{5}$ and Alexander Pym ${ }^{1,6^{*}}$

\begin{abstract}
Background: Pharmacokinetic interactions between rifampicin and protease inhibitors (Pls) complicate the management of HIV-associated tuberculosis. Rifabutin is an alternative rifamycin, for patients requiring Pls. Recently some international guidelines have recommended a higher dose of rifabutin (150 mg daily) in combination with boosted lopinavir (LPV/r), than the previous dose of rifabutin (150 mg three times weekly \{tiw\}). But there are limited pharmacokinetic data evaluating the higher dose of rifabutin in combination with LPV/r. Sub-optimal dosing can lead to acquired rifamycin resistance (ARR). The plasma concentration of 25-O-desacetylrifabutin (d-RBT), the metabolite of rifabutin, increases in the presence of Pls and may lead to toxicity.

Methods and results: Sixteen patients with TB-HIV co-infection received rifabutin $300 \mathrm{mg}$ QD in combination with tuberculosis chemotherapy (initially pyrazinamide, isoniazid and ethambutol then only isoniazid), and were then randomized to receive isoniazid and LPV/r based ART with rifabutin $150 \mathrm{mg}$ tiw or rifabutin $150 \mathrm{mg}$ daily. The rifabutin dose with ART was switched after 1 month. Serial rifabutin and d-RBT concentrations were measured after 4 weeks of each treatment. The median $\mathrm{AUC}_{0-48}$ and Cmax of rifabutin in patients taking $150 \mathrm{mg}$ rifabutin tiw was significantly reduced compared to the other treatment arms. Geometric mean ratio $(90 \% \mathrm{Cl})$ for $\mathrm{AUC}_{0-48}$ and $\mathrm{Cmax}$ was 0.6 (0.5-0.7) and 0.5 (0.4-0.6) for RBT $150 \mathrm{mg}$ tiw compared with RBT $300 \mathrm{mg}$ and 0.4 (0.4-0.4) and 0.5 (0.5-0.6) for RBT $150 \mathrm{mg}$ tiw compared with $150 \mathrm{mg}$ daily. 86\% of patients on the tiw rifabutin arm had an AUCO- $24<4.5 \mu \mathrm{g} . \mathrm{h} / \mathrm{mL}$, which has previously been associated with acquired rifamycin resistance (ARR). Plasma d-RBT concentrations increased 5 -fold with tiw rifabutin dosing and 15 -fold with daily doses of rifabutin. Rifabutin was well tolerated at all doses and there were no grade 4 laboratory toxicities. One case of uveitis (grade 4), occurred in a patient taking rifabutin 300 mg daily prior to starting ART, and grade 3 neutropenia (asymptomatic) was reported in 4 patients. These events were not associated with increases in rifabutin or metabolite concentrations.
\end{abstract}

Conclusions: A daily $150 \mathrm{mg}$ dose of rifabutin in combination with LPV/r safely maintained rifabutin plasma concentrations in line with those shown to prevent ARR.

Trial registration: ClinicalTrials.gov Identifier: NCT00640887

Keywords: Rifabutin, Pharmacokinetics, Lopinavir, Tuberculosis, HIV, DDI, Randomized, Clinical trial, Neutropenia, Uveitis

\footnotetext{
* Correspondence: alex.pym@k-rith.org

${ }^{1}$ TB Research Unit, Medical Research Council, Durban, South Africa

${ }^{6}$ KwaZulu-Natal Research Institute for Tuberculosis and HIV (K-RITH),

University of KwaZulu-Natal, Durban, South Africa

Full list of author information is available at the end of the article
} 


\section{Background}

Treating HIV associated tuberculosis remains a formidable challenge. In 2014, $13 \%$ of the 9 million incident cases of tuberculosis, and $25 \%$ of deaths from tuberculosis were in HIV-infected patients [1]. Combining efavirenz-based first-line antiretroviral therapy (ART) with rifampicin based tuberculosis chemotherapy significantly reduces mortality in these patients [2-4] and is safe and efficacious. However, as public sector ART expands in developing countries, an increasing number of patients are developing virological failure and require second-line ART with protease inhibitors [5,6]. Combining rifampicin and protease inhibitor-based second-line ART is problematic as rifampicin significantly reduces the bioavailability and increases the clearance of protease inhibitors by accelerating their metabolism via induction of cytochrome 3A4 (CYP3A4) enzymes. Increasing the dose of the protease inhibitor or co-administering higher doses of a CYP3A4 inhibitor to ameliorate this adverse drugdrug interaction have been thwarted by hepatotoxicity and other problems with tolerability $[7,8]$.

Rifabutin, a less potent inducer of CYP3A4 $[9,10]$, is recommended at $300 \mathrm{mg}$ daily as prophylaxis and treatment of Mycobacterium avium complex (MAC) and for the treatment of drug susceptible tuberculosis. Plasma concentrations of rifabutin are increased in the presence of protease inhibitors [11] therefore dose adjustments are recommended when rifabutin is combined with a protease inhibitor. Some recent guidelines recommend dosing rifabutin $150 \mathrm{mg}$ daily (QD) in combination with a ritonavir-boosted protease inhibitor [12], but others still recommend $150 \mathrm{mg}$ three time weekly (tiw) [13]. These differences in guidelines are due to the limited pharmacokinetic studies comparing the 2 dosing regimens of rifabutin and persisting concerns about the tolerability and toxicity of using higher doses of rifabutin [14]. Previous reports suggested that less frequent dosing at $150 \mathrm{mg}$ in HIV-positive tuberculosis patients can result in inadequate rifamycin concentrations [15,16], relapse [17] and acquired rifamycin resistance (ARR) [18]. Patients with rifabutin $\mathrm{AUC}_{0-24}<4.5 \mu \mathrm{g} . \mathrm{h} / \mathrm{mL}$ were identified as at the highest risk of ARR. The optimum pharmacokinetic parameter associated with treatment efficacy is unknown.

Elimination of rifabutin is primarily by metabolism via various routes, with deacetylation to d-RBT considered the most important. The d-RBT metabolite is known to have antibacterial activity [19] but may also contribute to toxicity, and is thought to be metabolized further in the liver by CYP 3A4. The present study was therefore undertaken to compare the bioavailability of rifabutin and d-RBT after two different dosing regimens of rifabutin (150 mg tiw and $150 \mathrm{mg}$ daily) in combination with ritonavir boosted lopinavir (LPV/r), the protease inhibitor most commonly used to treat HIV infection in South Africa.

\section{Methods}

\section{Study design}

An open-label, randomized, three-period, crossover drug interaction study was undertaken to investigate the pharmacokinetics of rifabutin with and without PI-based ART (Figure 1). The secondary objective was to assess the tolerability and safety of rifabutin and LPV/r. The Biomedical Research Ethics Committees of the Universities of Kwa-Zulu Natal and Cape Town, and the Ethics Committee of the International Union against Tuberculosis and Lung Disease (Paris) and the South African Medicines Control Council approved the study. The trial registration number was NCT00640887 (https://clinicaltrials.gov/).

\section{Recruitment}

Patients were recruited from local tuberculosis clinics in Kwa-Zulu Natal, South Africa. The study ran from February 2009 until October 2010. All patients provided written informed consent. Eligibility requirements were a diagnosis of pulmonary tuberculosis confirmed by microscopy or culture, HIV infection with CD4 lymphocyte count $\geq 50$ and $\leq 200$ cells $/ \mathrm{mm}^{3}$, weight $\geq 50 \mathrm{~kg}$ or a $\mathrm{BMI} \geq 18$, a Karnofsky score $\mathrm{Q} \geq 80 \%$ and no grade 3 or 4 clinical or laboratory findings according to DAIDS tables [20]. The CD4 restrictions for this study were a reflection of the South African guidelines for the initiation of ART in TB patients at the time the study was conducted [21]. Patients with CD4 counts below 50 were recommended to initiate therapy immediately whereas those with CD4 count between 50 and 200 were initiated at 2 months of TB therapy.

Only patients who completed and adhered to 6 weeks of standard intensive phase chemotherapy and had not received ART therapy in the preceding three months were enrolled. Patients with a previous tuberculosis episode within three years prior to the current episode, a history of prior treatment for MDR tuberculosis, concomitant opportunistic infection requiring additional antimicrobial treatment, a formal contraindication to any trial medication, diabetes mellitus requiring treatment, recreational drug or alcohol abuse, mental illness, total neutrophil count $<1200$ cells/L, hemoglobin $<6.8 \mathrm{~g} / \mathrm{dL}$, or liver function tests $>$ grade 2 , pregnancy or lactating women were excluded.

\section{Treatments under study}

At enrollment, six weeks after starting standard tuberculosis chemotherapy, rifampicin was switched to rifabutin $300 \mathrm{mg}$ daily (Figure 1). After two weeks of rifabutin, pyrazinamide and ethambutol were stopped and patients continued with daily doses of rifabutin $300 \mathrm{mg}$ in combination with isoniazid $300 \mathrm{mg}$. After two more weeks, the first pharmacokinetic evaluation (PK1) was carried 


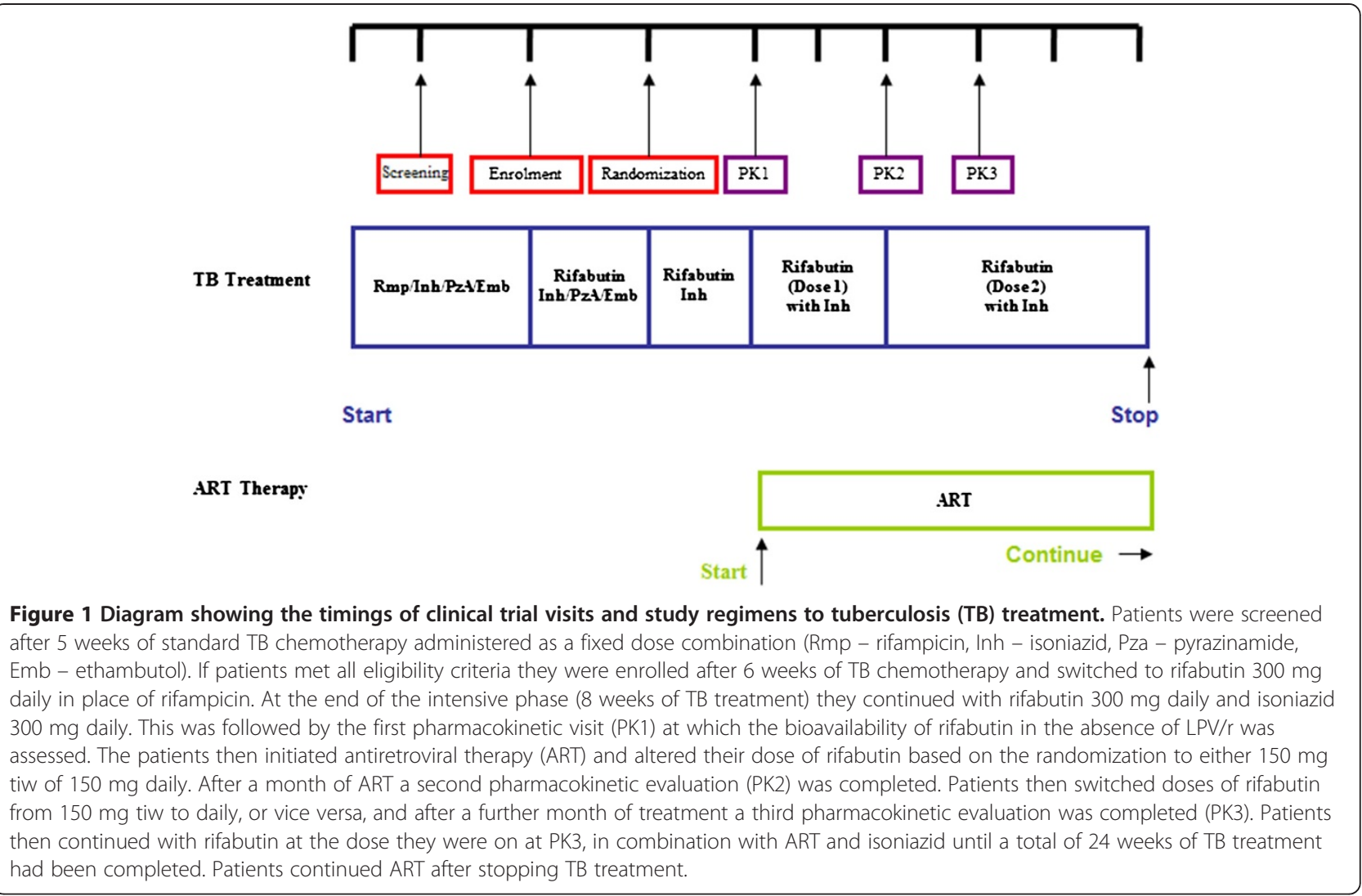

out and patients were randomized to one of two different rifabutin dose sequences together with daily doses of isoniazid and ART comprising LPV/r (400/100 mg) plus lamivudine (150 $\mathrm{mg}$ bd) and stavudine (30 mg bd). Half the patients received rifabutin $150 \mathrm{mg}$ tiw for 4 weeks before being switched to rifabutin $150 \mathrm{mg}$ daily after a second pharmacokinetic evaluation (PK2). A third pharmacokinetic evaluation (PK3) took place after 4 weeks and they remained on this dose of rifabutin until completion of tuberculosis treatment. Half the patients received the two rifabutin doses in a reverse sequence.

Physical examinations and laboratory investigations were done at screening, after 1 month of rifabutin (trial day 28 - PK1), after 1 month of ART and rifabutin (trial day 56 - PK2), after 2 months of ART and rifabutin (trial day $84-\mathrm{PK} 2$ ) and 2 weeks before the end of TB treatment (trial day 112) as shown in Figure 1. Upon completion of the trial, patients were referred to local antiretroviral clinics for further management. Pfizer (South Africa) supplied the rifabutin (Mycobutin $\left.{ }^{\otimes}\right) 150 \mathrm{mg}$ capsules and the new film-coated tablet formulation of LPV/r, Aluvia ${ }^{\circ}$ was purchased from Abbott Laboratories (USA).

\section{Sample size}

Based on the $\mathrm{AUC}_{0-24}$ for rifabutin determined in previous studies, it was estimated that a sample size of 12 participants had a power of $80 \%$ to detect a $20 \%$ difference between the mean $\mathrm{AUC}_{0-24}$ for rifabutin with and without ART. The sample size was calculated on the assumption that 16 enrolled participants would result in a minimum of 12 evaluable subjects. The additional 4 patients in each arm were recruited as it was thought that there may be drop out of patients before completing 3 full pharmacokinetic visits.

\section{Pharmacokinetic sampling}

All patients were admitted before each pharmacokinetic occasion and were fasted from midnight. A standard hospital breakfast (oats with 2 slices of toast and tea) was served $2 \mathrm{~h}$ after drug ingestion. Blood draws were done at $0,2,3,4,5,6,8,12,24$ and $48 \mathrm{~h}$ after drug ingestion. The samples were placed on ice immediately and centrifuged at $3000 \mathrm{rpm}$ at $4^{\circ} \mathrm{C}$ for 10 minutes. Separated plasma was stored immediately at $-70^{\circ} \mathrm{C}$ until batch analysis.

\section{Drug analyses}

Rifabutin and d-RBT were analyzed with a validated LC/ MS/MS assay [14]. Rifaximin was used as internal standard at a concentration of $100 \mathrm{ng} / \mathrm{ml}$. Gradient chromatography was performed on a Phenomenex, Luna $5 \mu \mathrm{m}$ PFP (2), $100 \mathrm{~A}, 50 \mathrm{~mm} \times 2 \mathrm{~mm}$ analytical column, using 
acetonitrile and $0.1 \%$ formic acid as mobile phase, and a flow rate of $500 \mu \mathrm{l} / \mathrm{min}$. An AB Sciex API 3200 mass spectrometer monitored protonated ions at $\mathrm{m} / \mathrm{z} 847.4$ to the product ions at $\mathrm{m} / \mathrm{z} 95.1$ for rifabutin, at $\mathrm{m} / \mathrm{z} 805.4$ to the product ions at $\mathrm{m} / \mathrm{z} 95.1$ for $\mathrm{d}-\mathrm{RBT}$, and at $\mathrm{m} / \mathrm{z}$ 786.3 to the product ions $\mathrm{m} / \mathrm{z} 151.1$ for rifaximin. Rifabutin and d-RBT accuracies were between $99.1 \%$ and $109.0 \%$ during inter-batch validation. The co-efficient of variation during inter-batch validation was less than $9.2 \%$. The calibration range for rifabutin was between $3.91 \mathrm{ng} / \mathrm{ml}$ and $1000 \mathrm{ng} / \mathrm{ml}$, and for d-RBT between $0.780 \mathrm{ng} / \mathrm{ml}$ and $200 \mathrm{ng} / \mathrm{ml}$. The intra- and inter-batch accuracy statistics of the rifabutin and d-RBT assay validation were between $93.3 \%$ and $111.5 \%$, and between $99.1 \%$ and $109 \%$. The co-efficient of variation was less than $13.8 \%$.

Plasma lopinavir concentrations were quantified by a validated LCMS/MS method previously described by Chi et al. [22]. The calibration curve was linear over the range from 0.05 to $20 \mathrm{mg} / \mathrm{L}$. Samples with a concentration of $>20 \mathrm{mg} / \mathrm{L}$, were diluted and re-analyzed. Any sample below the LLQ was reported as $0.5 \mathrm{X}$ LLQ for analysis. The intra- and inter-batch accuracy statistics of the lopinavir assay validation were between $95.0 \%$ and $96.4 \%$, and between $96.2 \%$ and $99.1 \%$. The coefficient of variation $(\% \mathrm{CV})$ was less than $3.9 \%$.

\section{Pharmacokinetic analysis}

The main pharmacokinetic measures for rifabutin, d-RBT and lopinavir were derived by non-compartmental analysis using Stata (StataCorp. 2009. Stata Statistical Software: Release 11. College Station, TX: StataCorp LP). The peak concentration $\left(C_{\max }\right)$, and time to $C_{\max }\left(T_{\max }\right)$ were obtained directly from concentration-time profiles. Drug concentrations at the end of a dosing interval are reported as $\mathrm{C}_{\text {min }}$ and pre-dose concentrations as $\mathrm{C}_{0}$. The steady-state AUC from time $0 \mathrm{~h}$ to the last quantifiable sample at $24 \mathrm{~h}$ $\left(\mathrm{AUC}_{0-24}\right)$ or $48 \mathrm{~h}\left(\mathrm{AUC}_{0-48}\right)$ for rifabutin and $12 \mathrm{~h}$ $\left(\mathrm{AUC}_{0-12}\right)$ for $\mathrm{LPV} / \mathrm{r}$ were calculated by the linear trapezoidal method. The apparent total oral clearance of rifabutin from plasma at steady state $(\mathrm{CL} / \mathrm{F})$ was calculated by dose/AUC.

\section{Statistics}

For statistical analysis, the $\mathrm{AUC}_{0-24}$ was log-transformed. A linear mixed model with two doses (high and low), day (2 and 3), the sequence of the doses, $\log \mathrm{AUC}_{0-24}$ and id nested within sequence was used. As there was no significant effect of sequencing of the doses (whether the patients received the tiw dose before the daily dose of rifabutin or vice versa), the two corresponding doses from each arm were pooled for further analysis. A paired t-test was used to compare the $\mathrm{AUC}_{0-24}$ for the $150 \mathrm{mg}$ daily dose with that for $150 \mathrm{mg}$ tiw and $300 \mathrm{mg}$ daily doses. An $\mathrm{AUC}_{0-48}$ was derived for the $150 \mathrm{mg}$ daily and $300 \mathrm{mg}$ daily doses by doubling the $\mathrm{AUC}_{0-24}$. This was compared with the $\mathrm{AUC}_{0-48}$ for the $150 \mathrm{mg}$ tiw dose using a paired t-test. The dosing interval is 48 hours for the tiw dose for 2 of 3 doses.

To calculate geometric mean ratios (GMR) for AUC, log means and 90\% confidence limits were back transformed and presented in their original units as geometric means. Geometric mean ratios for the AUC of rifabutin: $150 \mathrm{mg}$ daily with LPV/r / $300 \mathrm{mg}$ daily, and $150 \mathrm{mg}$ tiw with LPV/300 mg daily, respectively, were computed. A P-value $<0.05$ was considered significant. Inter-patient variability was measured by co-efficient of variation (\%CV) that was calculated as $\left.\{100 \mathrm{X} \text { (e (var est) }-1)^{1 / 2}\right\}$. Baseline and final log viral loads and $\mathrm{CD} 4^{+}$counts were compared using paired t-tests.

\section{Results}

\section{Patient demographics}

Sixteen patients received LPV/r therapy with rifabutin. Two patients were prematurely withdrawn from the study and were therefore not evaluable for pharmacokinetic analysis, one due to uveitis and another due to noncompliance with trial medication. All patients were Black South Africans and (64\%) were male. All patients had not previously received any antiretroviral therapy. The evaluable subjects' mean (SD) age was 31.5 (5.8) years, weight was 59.9 (9.7) kg, height was $160(7.7) \mathrm{cm}$, BMI was 23.3 (2.6), Karnofsky score Q was $100 \%$ (100) and CD4 $4^{+}$ lymphocyte count was 150.9 (12.1) cells $/ \mathrm{mm}^{3}$.

\section{Rifabutin and 25-O-desacetylrifabutin pharmacokinetic analysis}

The main pharmacokinetic parameters for rifabutin and d-RBT are summarized in Table 1 and shown graphically in Figures 2 and 3. The $\mathrm{AUC}_{0-24}$ of rifabutin $150 \mathrm{mg}$ daily with $\mathrm{LPV} / \mathrm{r}$ was significantly higher when compared to the $\mathrm{AUC}_{0-24}$ of rifabutin $300 \mathrm{mg}$ daily in the absence of $\mathrm{LPV} / \mathrm{r}(\mathrm{p}=0.004)$. In contrast, the $\mathrm{AUC}_{0-48}$ of rifabutin $150 \mathrm{mg}$ tiw with $\mathrm{LPV} / \mathrm{r}$ was significantly lower than the $\mathrm{AUC}_{0-48}$ of rifabutin $300 \mathrm{mg}$ daily $(\mathrm{p}=0.0001)$. These differences were large as demonstrated by the GMR (Table 2). The GMR (90\% CI) for $\mathrm{AUC}_{0-48}$ was $0.6(0.5-0.7)$ and $0.5(0.4-0.6)$ for rifabutin $150 \mathrm{mg}$ tiw compared with rifabutin $300 \mathrm{mg}$. For the comparison of the $150 \mathrm{mg}$ daily dose of rifabutin with the $300 \mathrm{mg}$ dose the GMR of the $\mathrm{AUC}_{0-24}$ was 1.6 (1.4-1.9). Wide interpatient variability was observed in rifabutin AUC for all three doses (Table 2). The \%CV was $24 \%$ for the $300 \mathrm{mg}$ dose, $46 \%$ for rifabutin $150 \mathrm{mg}$ daily plus LPV/r and 52\% for rifabutin $150 \mathrm{mg}$ tiw plus LPV/r.

The $C_{\max }$ of rifabutin $150 \mathrm{mg}$ tiw with $\mathrm{LPV} / \mathrm{r}$ was also significantly lower when compared to the $150 \mathrm{mg}$ daily dose with $\mathrm{LPV} / \mathrm{r}(\mathrm{P}=0.01)$ and the $300 \mathrm{mg}$ daily dose 
Table 1 Pharmacokinetic parameters for rifabutin and 25-0-desacetylrifabutin for each study treatment

\begin{tabular}{|c|c|c|c|}
\hline Treatment period & Rifabutin 300 mg & Rifabutin 150 mg tiw plus LPV/r & Rifabutin $150 \mathrm{mg}$ daily plus LPV/r \\
\hline \multicolumn{4}{|l|}{ Rifabutin ( $n=14)$} \\
\hline$A \cup C_{0-24}(\mathrm{ng} \cdot \mathrm{h} / \mathrm{mL})$ & $3052.9(2650.2-3431.5)$ & $2307.5(1767.5-3884.0)$ & $4766.0(3950.5-6099.5)$ \\
\hline $\mathrm{AUC}_{0-48}(\mathrm{ng} \cdot \mathrm{h} / \mathrm{mL})$ & $6105.8(5300.4-6863.0)^{*}$ & $3402.1(2809.2-6092.0)$ & $9532.0(2238.2-22425.4)^{*}$ \\
\hline$C_{\max }(\mathrm{ng} / \mathrm{mL})$ & $291.5(250.0-377.0)$ & $167.5(87.8-294.0)$ & $311.0(258.0-376.0)$ \\
\hline $\mathrm{T}_{\max }(\mathrm{h})$ & $3.0(3.0-4.0)$ & $3.5(3.0-5.0)$ & $3.0(3.0-4.0)$ \\
\hline$C_{0}(\mathrm{ng} / \mathrm{mL})$ & $59.0(36.4-78.6)$ & $49.1(27.7-58.9)$ & $176.5(149.0-195.0)$ \\
\hline$C_{\min } 24 \mathrm{~h}(\mathrm{ng} / \mathrm{mL})$ & $60.7(40.6-68.8)$ & $70.7(45.7-96.6)$ & $133.0(105.0-191.0)$ \\
\hline$C_{\min } 48 \mathrm{~h}(\mathrm{ng} / \mathrm{mL})$ & - & $37.0(26.6-70.0)$ & - \\
\hline $\mathrm{CL} / \mathrm{F}(\mathrm{L} / \mathrm{h})$ & $98.3(87.4-113.2)$ & $65.2(38.6-85.0)$ & $31.5(25.0-38.0)$ \\
\hline $\mathrm{AUC}_{0-24}(\mathrm{ng} . \mathrm{h} / \mathrm{mL})($ Rifabutin + Metabolite) & $3402.3(2900.3-3717.2)$ & $3937.2(2424.6-6772.7)$ & $8753.0(7771.7-11505.0)$ \\
\hline \multicolumn{4}{|l|}{ d-RBT $(n=14)$} \\
\hline$A \cup C_{0-24}(\mathrm{ng} \cdot \mathrm{h} / \mathrm{mL})$ & $273.3(235.7-344.1)$ & $1565.5(1105.5-2567.3)$ & $4118.0(2678.2-5405.5)$ \\
\hline$A \cup C_{0-48}(\mathrm{ng} \cdot \mathrm{h} / \mathrm{mL})$ & $546.6(471.4-688.2)^{*}$ & $2318.2(1722.9-4685.9)$ & $8236.0(5356.4-10811.0)^{*}$ \\
\hline$C_{\max }(\mathrm{ng} / \mathrm{mL})$ & $32.5(25.2-37.7)$ & $77.2(58.6-128)$ & $236.5(159.0-274.0)$ \\
\hline $\mathrm{T}_{\max }(\mathrm{h})$ & $3.0(3.0-4.0)$ & $5.0(4.0-6.0)$ & $4.0(3.0-3.0)$ \\
\hline $\mathrm{C}_{0}(\mathrm{ng} / \mathrm{mL})$ & $5.1(2.7-6.6)$ & $44.6(31.7-68.9)$ & $186.0(115.0-232.0)$ \\
\hline $\mathrm{C}_{\min } 24 \mathrm{~h}(\mathrm{ng} / \mathrm{mL})$ & $5.0(3.4-5.8$ & $63.9(42.7-101.0)$ & $155.0(53.6-206.0)$ \\
\hline$C_{\min } 48 \mathrm{~h}(\mathrm{ng} / \mathrm{mL})$ & - & $35.4(27.7-81.0)$ & - \\
\hline
\end{tabular}

Parameters are median values (interquartile range).

*calculated by $2 \mathrm{X} \mathrm{AUC}_{0-24}$.

$\mathrm{RBT}=$ rifabutin

$\mathrm{d}-\mathrm{RBT}=25$-O-desacetylrifabutin

$\mathrm{LPV} / \mathrm{r}=$ lopinavir/ritonavir based ART.

tiw $=$ three times per week.

$A \cup C=$ area under the curve.

$\mathrm{C}_{\max }=$ maximum concentration in plasma

$T_{\max }=$ time at which maximum plasma attained.

$\mathrm{CL} / \mathrm{F}=$ clearance.

$\mathrm{C}_{0}=$ pre-dose concentration.

$\mathrm{C}_{\min }=$ trough concentration.

without $\mathrm{LPV} / \mathrm{r} \quad(\mathrm{P}=0.01)$. The GMR $(90 \% \mathrm{CI})$ for Cmax was 0.5 (0.4-0.6) for RBT $150 \mathrm{mg}$ tiw compared with RBT $300 \mathrm{mg}$ and 0.5 (0.5-0.6) for RBT $150 \mathrm{mg}$ tiw compared with $150 \mathrm{mg}$ daily. The median $\mathrm{C}_{\text {min }}$ for rifabutin $300 \mathrm{mg}$ was $60.7 \mathrm{ng} / \mathrm{mL}$ (IQR, 40.6-68.8 ng/mL). The $C_{\min }$ values increased in the presence of $\mathrm{LPV} / \mathrm{r}$ with daily dosing of rifabutin but dropped significantly with the tiw dose. Rifabutin clearance was significantly reduced in the presence of LPV/r ( $p=0.001$ for daily and $p=0.002$ tiw rifabutin dosing) compared to $300 \mathrm{mg}$ rifabutin given alone.

Without lopinavir, d-RBT concentrations were $11 \%$ of the parent drug. Plasma d-RBT concentrations increased 5-fold with tiw rifabutin dosing and 15-fold with daily doses of rifabutin (Figure 3 ). The total antimicrobial moiety (combined $\mathrm{AUC}_{0-24}$ of rifabutin and metabolite) for rifabutin at $150 \mathrm{mg}$ tiw with ART was 1.2 times greater than for $300 \mathrm{mg}$ rifabutin and 2.6 times less than for $150 \mathrm{mg}$ daily with ART.

\section{Lopinavir pharmacokinetic analysis}

Lopinavir pharmacokinetic measures are shown in Table 3 and Figure 4. Median lopinavir trough $\left(\mathrm{C}_{0}\right)$ concentrations were above the recommended lower limit for ART-naïve patients of $1 \mu \mathrm{g} /$ [23]. Although there was a trend to higher lopinavir concentrations with the once daily dosing of rifabutin, the differences in $\mathrm{AUC}_{0-12}$ and $\mathrm{C}_{\max }$ between the two doses were not significant. Double peaks were observed in the individual lopinavir concentration-time profiles with both doses of rifabutin.

\section{Response to TB/HIV treatment}

Three patients were culture positive after two months of tuberculosis therapy and none culture positive at the end of therapy. The mean final $\mathrm{CD}^{+}$count at the end of tuberculosis therapy was 253.8 (42.4) cells $/ \mathrm{mm}^{3}$, and significantly higher $(\mathrm{p}=0.03)$ than baseline. The mean (SD) viral load dropped significantly $(\mathrm{p}<0.001)$ by $2.7 \log 10$ copies and 8 patients had viral loads $<500$ copies $/ \mathrm{ml}$. 


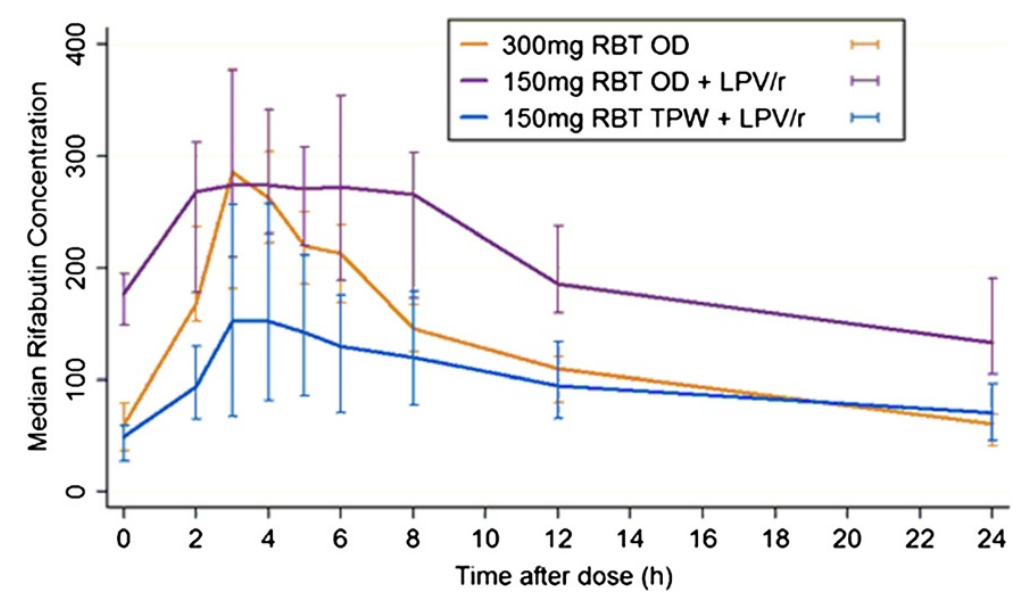

Figure 2 Rifabutin median concentration-time profiles. Median rifabutin (RBT) concentrations for the three pharmacokinetic evaluations in 14 patients. The orange line corresponds to the dosing of RBT at $300 \mathrm{mg}$ without ART; the blue line to RBT dosing at $150 \mathrm{mg}$ tiw with ART and the purple line to dosing with $150 \mathrm{mg}$ of RBT daily with ART. The bars represent interquartile range (IQR).

\section{Adverse events}

Adverse events (AE) were analyzed for all sixteen patients. Rifabutin was well tolerated at all doses and there was only one withdrawal because of an adverse event (uveitis). There were two serious adverse events (bacterial meningitis and pyelonephritis), both considered unrelated to rifabutin by the study team. Grade 2 uveitis occurred in one patient after 1 month of rifabutin, coinciding with the start of ART, and resolved with no sequelae after withdrawal of medication. Her $\mathrm{AUC}_{0-24}$ and $\mathrm{C}_{\max }$ values for rifabutin were within the interquartile range. The commonest laboratory AE was neutropenia. Grade 3 neutropenia occurred on 7 occasions in 5 patients (Table 4). There were 2 grade 3 elevations in transaminases and amylase. There were no grade 4 laboratory events.

\section{Discussion}

The results of this study show that there are substantial differences in the $\mathrm{AUC}_{0-24}$ of rifabutin obtained with the two different dosing regimens in combination with $\mathrm{LPV} / \mathrm{r}$. The daily dose of $150 \mathrm{mg}$ resulted in a more than two fold increase in the $\mathrm{AUC}_{0-24}$ when compared to the three times a week dose. The difference between the two doses was even greater when comparing the $\mathrm{AUC}_{0-48}$. There is a lack of conventional efficacy data in support of a particular dose or target pharmacokinetic parameter for rifabutin [24], but there is convincing evidence that intermittent rifamycin therapy is associated with tuberculosis relapse and rifamycin resistance, especially in subjects with low CD4 counts [17,18,25-27]. In TBTC study [18], TB-HIV co-infected patients who had $\mathrm{AUC}_{0-24}<4.5 \mu \mathrm{g} . \mathrm{h} / \mathrm{mL}$ were

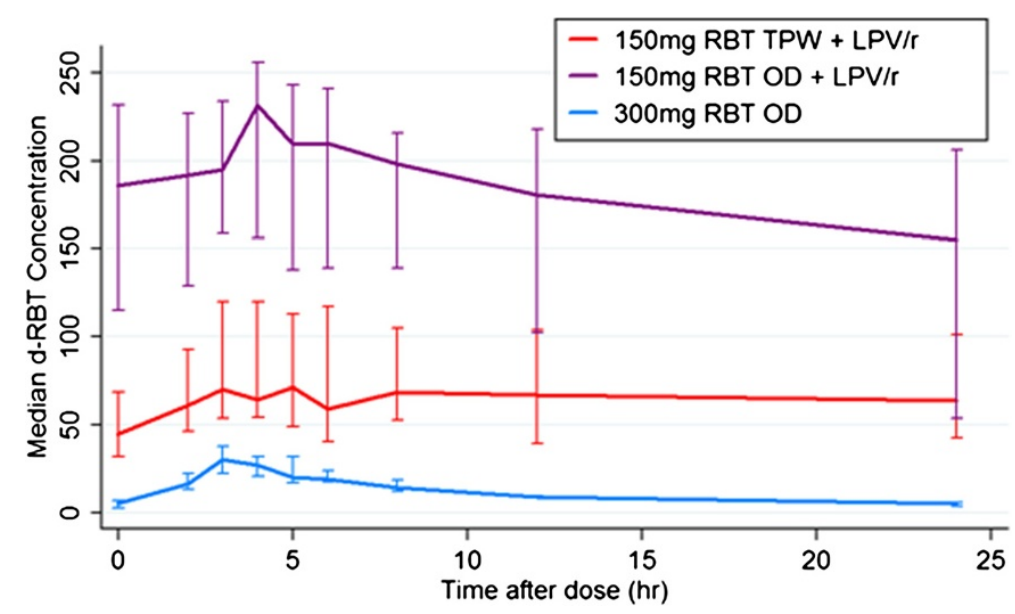

Figure 3 25-O-desacetylrifabutin median concentration-time profiles. Median 25-O-desacetylrifabutin (d-RBT) concentrations for the three pharmacokinetic evaluations in 14 patients. The bars represent interquartile range (IQR). The blue line corresponds to the dosing of RBT at $300 \mathrm{mg}$ without ART; the red line to RBT dosing at $150 \mathrm{mg}$ tiw with LPV/r based ART and the purple line to dosing with $150 \mathrm{mg}$ of RBT daily. 
Table 2 Geometric mean ratios of rifabutin and 25-0-desacetylrifabutin parameters with and without antiretroviral therapy

\begin{tabular}{|c|c|c|c|}
\hline & \multicolumn{3}{|l|}{ GMR $(90 \% \mathrm{CI})$} \\
\hline & $\begin{array}{l}\text { RBT } 150 \mathrm{mg} \text { tiw } \\
\text { with RBT } 300 \mathrm{mg} \\
\text { daily }\end{array}$ & $\begin{array}{l}\text { RBT } 150 \mathrm{mg} \text { tiw } \\
\text { with RBT } 150 \mathrm{mg} \\
\text { daily }\end{array}$ & $\begin{array}{l}\text { RBT } 150 \mathrm{mg} \text { daily } \\
\text { with RBT } 300 \mathrm{mg} \\
\text { daily }\end{array}$ \\
\hline $\mathrm{AUC}_{0-24}$ & $0.8(0.7-0.9)$ & $0.4(0.5-0.5)$ & $1.6(1.4-1.9)$ \\
\hline$A \cup C_{0-48^{*}}$ & $0.6(0.5-0.7)$ & $0.4(0.4-0.4)$ & $\mathrm{n} / \mathrm{a}$ \\
\hline$C_{\max }(\mathrm{ng} / \mathrm{mL})$ & $0.5(0.4-0.6)$ & $0.5(0.5-0.6)$ & $1.0(0.9-1.0)$ \\
\hline $\mathrm{C}_{0}(\mathrm{ng} / \mathrm{mL})$ & $0.7(0.5-0.9)$ & $0.2(0.1-0.3)$ & $3.4(3.7-3.1)$ \\
\hline$C_{\min } 24 h(n g / m L)$ & $1.2(1.0-1.4)$ & $0.5(0.4-0.5)$ & $2.7(2.2-3.2)$ \\
\hline
\end{tabular}

*calculated by 2 times the $\mathrm{AUC}_{0-24}$ for the RBT $300 \mathrm{mg}$ daily and RBT $150 \mathrm{mg}$ daily arms.

n/a - Not applicable.

GMR - Geometric mean ratio.

$90 \% \mathrm{Cl}-90 \%$ confidence interval.

RBT $150 \mathrm{mg}$ tiw - rifabutin dose of $150 \mathrm{mg}$ three times per week (tiw) in combination with lopinavir/ritonavir based ART and isoniazid.

RBT $150 \mathrm{mg}$ daily - rifabutin dose of $150 \mathrm{mg}$ daily in combination with lopinavir/ritonavir based ART and isoniazid.

RBT $300 \mathrm{mg}$ daily - rifabutin dose of $300 \mathrm{mg}$ daily in combination with isoniazid.

at higher risk of ARR. Of the patients who relapsed or failed therapy $83 \%$ developed ARR as opposed to $33 \%$ who had AUC's above this threshold value. In this study, $71 \%$ patients on rifabutin $150 \mathrm{mg}$ daily had $\mathrm{AUC}_{0-24}$ values $>4.5 \mu \mathrm{g} . \mathrm{h} / \mathrm{mL}$ compared to $14 \%$ on rifabutin tiw dosing. Similarly the $C_{\min }$ values of rifabutin 48 hours after dosing tiw are significantly lower than the $C_{\min }$ values for $300 \mathrm{mg}$ daily and $150 \mathrm{mg}$ daily. On the basis of prevention of resistance our data support the guidelines that recommend a dose of rifabutin $150 \mathrm{mg}$ daily in combination with protease inhibitors [28].

The $\mathrm{AUC}_{0-24}$ and $\mathrm{C}_{\max }$ of $\mathrm{d}$-RBT were significantly increased in the presence of $\mathrm{LPV} / \mathrm{r}$ in keeping with previous treatment $[29,30]$ and healthy volunteer studies $[11,31,32]$. There were respective increases in exposure

Table 3 Pharmacokinetic parameters for lopinavir for each study treatment

\begin{tabular}{lll}
\hline \multirow{2}{*}{ Parameter } & \multicolumn{2}{l}{ Median (Interquartile range) } \\
\cline { 2 - 3 } & $\begin{array}{l}\text { RBT 150 mg tiw } \\
\text { plus LVP/r }\end{array}$ & $\begin{array}{l}\text { RBT 150 mg daily } \\
\text { plus LPV/r }\end{array}$ \\
\hline AUC $_{0-12}(\mu \mathrm{g} . \mathrm{h} / \mathrm{mL})$ & $139.5(103.8-163.9)$ & $160.1(129.1-181.9)$ \\
$C_{\max }(\mathrm{ng} / \mathrm{mL})$ & $15.8(12.9-17.1)$ & $18.1(14.5-19.6)$ \\
$\mathrm{T}_{\max }(\mathrm{h})$ & $2.0(2.0-3.0)$ & $2.0(2.0-3.0)$ \\
$\mathrm{C}_{0}(\mu \mathrm{g} / \mathrm{mL})$ & $9.8(3.5-14.0)$ & $11.4(9.9-15.2)$ \\
$C_{\min }(\mu \mathrm{g} / \mathrm{mL})$ & $7.4(4.5-10.0)$ & $9.4(7.2-11.6)$ \\
\hline
\end{tabular}

$\mathrm{RBT}=$ rifabutin.

$\mathrm{LPV} / \mathrm{r}=$ lopinavir/ritonavir.

tiw $=$ three times per week.

AUC $=$ area under the curve.

$\mathrm{C}_{\max }=$ maximum concentration in plasma .

$\mathrm{T}_{\max }=$ time at which maximum plasma attained

$\mathrm{C}_{0}=$ pre-dose concentration.

$\mathrm{C}_{\min }=$ trough concentration. to the metabolite of approximately 5 - and 15 -fold when rifabutin $150 \mathrm{mg}$ was given tiw or daily with $\mathrm{LPV} / \mathrm{r}$ and are probably due to the presence of ritonavir. Ritonavir is a potent inhibitor of CYP3A4, which metabolizes d-RBT. d-RBT is known to have significant anti-mycobacterial activity and could contribute to the regimen efficacy [19]. These elevations of the d-RBT metabolite could led to an increase in adverse drug reactions. We were unable to show a significant association between plasma rifabutin and d-RBT concentration and adverse events such as neutropenia or elevated transaminases however the numbers of patients are few and larger studies are required to establish the safety of the rifabutin $150 \mathrm{mg}$ daily dose. It will also be important to investigate the interaction of RBT in combination with other antiretrovirals [33].

Although the currently recommended dose of rifabutin for the treatment of pulmonary tuberculosis is $300 \mathrm{mg}$ daily there are few pharmacokinetic data from HIV infected African tuberculosis patients treated with this dose. The median rifabutin $\mathrm{AUC}_{0-24}$ and $\mathrm{C}_{\max }$ values from this study are comparable to previous studies of rifabutin $300 \mathrm{mg}$ daily in HIV-infected patients [15,34-36]. The pharmacodynamic-pharmacokinetic (PKPD) relationship for rifabutin has not been comprehensively studied so it is not clear how the reduced AUC of the $150 \mathrm{mg}$ tiw dose relative to the $300 \mathrm{mg}$ dose without ART reported here would impact on tuberculosis treatment outcomes. It is still uncertain if $C_{\max }$ or AUC is the critical pharmacodynamic measure for rifamycins. Mitchison [37] and others reported the $\mathrm{C}_{\max } / \mathrm{MIC}$ to be the best PKPD measure whereas subsequent murine and hollow fibre models [38,39], and early bactericidal activity studies in humans [40] found that the $\mathrm{AUC}_{0-24} / \mathrm{MIC}$ ratio was a superior parameter.

Previous studies of the pharmacokinetic interaction of rifabutin with $\mathrm{LPV} / \mathrm{r}$ in HIV infected individuals have mostly been small case series or involved an adaptive design in which only selected patients were exposed to the higher dose of rifabutin $[15,16,41]$. One previous study has reported on the rifabutin pharmacokinetics in combination with LPV/r (Aluvia) but in patients initiating rifabutin at the start of therapy [42]. This study was conducted in Vietnam in a different population group but also reported that the $150 \mathrm{mg}$ tiw dose was potentially sub therapeutic when compared to the $150 \mathrm{mg}$ daily dose or the $300 \mathrm{mg}$ dose without ART. Similar to that study we adopted a cross-over design in which all patients received 3 full pharmacokinetic assessments with rifabutin alone and at two different rifabutin doses in combination with ART allowing us to formally compare the different dosing strategies and reduce intra-patient variability. However there are limitations to our study. Although patients received rifabutin for a total of 18 weeks our numbers are small so it is necessary to be cautious in 


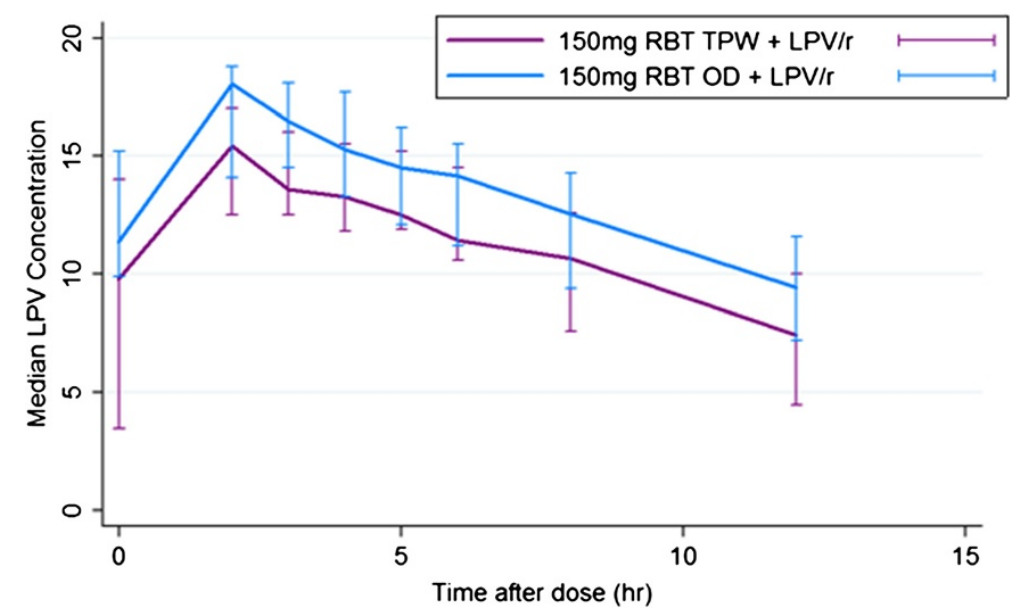

Figure 4 Median concentration-time profile of boosted lopinavir administered with two different doses of rifabutin. The median lopinavir (LPV) concentrations for 14 patients administered 2 different concentrations of rifabutin (RBT). Blue line corresponds to a RBT dose of $150 \mathrm{mg}$ daily and the purple line to $150 \mathrm{mg}$ tiw. LPV/r corresponds to boosted lopinavir. The bars represent interquartile range (IQR).

drawing definitive conclusions about the safety of rifabutin at the higher dose. We included immune-suppressed HIV positive patient but not those with CD4 count less than 50 , and it is conceivable that the pharmacokinetics and tolerability of rifabutin may be different in the most highly immune-suppressed group of patients.

Although the higher dose (150 mg daily) used in this study resulted in rifabutin levels that reduce the risk of resistance it is important to emphasis that the approximately 15 fold increase in the d-RBT metabolite might result in an increase in adverse events. Neutropenia and uveitis have previously been identified as severe adverse events associated with the co-administration of rifabutin with a CYP3A4 inhibitor [43-47]. A recent paediatric clinical trial of rifabutin in combination with $\mathrm{LPV} / \mathrm{r}$ was stopped due to a high frequency of grade 4 neutropenia [14]. An advantage of this study is that patients remained on study doses for sixteen weeks allowing a safety evaluation to be made over a longer duration. In this study the combinations of rifabutin and LPV/r were generally well tolerated with no grade 4 toxicities apart from 2 clinical serious adverse events reported by the study investigators as unrelated to rifabutin. Neutropenia was a common adverse event and has been reported predominantly in previous studies on healthy volunteers, but there were no grade 4 cases. Although there was a significant fall in the neutrophil count during the course of the trial most of this decline occurred in the first few weeks of rifabutin therapy prior to the initiation of ART and we did not find a significant association between neutropenia and plasma

Table 4 Timing of selected grade 3 laboratory adverse events

\begin{tabular}{|c|c|c|c|c|c|}
\hline Subject & AE Grade & $\mathrm{AE}$ & RBT dose at time of $\mathrm{AE}$ & Arm & Days on RBT \\
\hline 148 & 3 & AST increased & 150 mg daily & Low-High & 106 \\
\hline 148 & 3 & Amylase increased & 150 mg daily & Low-High & 113 \\
\hline 171 & 3 & Neutropenia & 300 mg daily & Low-High & 29 \\
\hline 182 & 3 & Neutropenia & 300 mg daily & Low-High & 27 \\
\hline 204 & 3 & Neutropenia & 150 mg daily & High-Low & 57 \\
\hline 204 & 3 & Neutropenia & $150 \mathrm{mg}$ tiw & High-Low & 112 \\
\hline 242 & 3 & Neutropenia & 300 mg daily & High-Low & 28 \\
\hline 242 & 3 & Neutropenia & 150 mg daily & High-Low & 53 \\
\hline 242 & 3 & AST increased & $150 \mathrm{mg}$ tiw & High-Low & 96 \\
\hline 242 & 3 & Amylase increased & $150 \mathrm{mg}$ tiw & High-Low & 119 \\
\hline 250 & 3 & Neutropenia & 150 mg daily & Low-High & 77 \\
\hline
\end{tabular}

$\mathrm{AE}$ - adverse event.

RBT - rifabutin.

ARM - refers to the sequencing order of the rifabutin dosing in combination with ART.

tiw- three times per week. 
rifabutin concentrations. Neutropenia is also the most common side effect of cotrimoxazole therapy in HIV- infected patients [48] and all patients in the present study were prescribed cotrimoxazole $960 \mathrm{mg}$ daily as prophylaxis. The majority of the patients started cotrimoxazole at enrollment and this would have contributed to the declining neutrophil count seen in this study. Uveitis occurred only once in a participant who had been taking $300 \mathrm{mg}$ rifabutin and was not associated with high serum concentrations of drug suggesting it could have been HIV related rather than drug related. However the number of patients are small in this study so the safety of the $150 \mathrm{mg}$ daily rifabutin dose needs to be established in a larger cohort.

The activity of protease inhibitors is influenced by their concentrations in plasma [49] therefore the pharmacokinetics of $\mathrm{LPV} / \mathrm{r}$ were evaluated in the presence of rifabutin. The median LPV/r AUC ${ }_{0-12}, \mathrm{C}_{\text {max }}, \mathrm{C}_{0}$ and $\mathrm{C}_{12}$ obtained in this study when LPV/r was administered with two different doses of rifabutin are consistent with historical control data [50]. Secondary peaks were observed in the timeconcentration profiles of LPV/r, usually within 4 hours of drug ingestion, similar to patterns observed in other studies. In both dosing arms, median LPV/r trough $\left(\mathrm{C}_{0}\right)$ concentrations at steady state were above the recommended lower limit for ART-naïve patients of $1 \mu \mathrm{g} / \mathrm{mL}$ [23] and therapeutic $\mathrm{LPV} / \mathrm{r}$ trough $\left(\mathrm{C}_{0}\right)$ and $\mathrm{C}_{\min }\left(\mathrm{C}_{12}\right)$ concentrations were achieved in all participants with both doses of rifabutin.

\section{Conclusions}

In conclusion this study supports the recent change to some guidelines for the dosing of rifabutin in combination with $\mathrm{LPV} / \mathrm{r}$ [28]. The high proportion of participants on the $150 \mathrm{mg}$ tiw arm who failed to achieve rifabutin concentrations that prevented the emergence of drug resistance when the drug is dosed twice weekly is concerning. Although escalating the rifabutin dose after therapeutic drug monitoring is a viable option in resource rich settings, it is impractical in many regions of the world where HIV and TB are endemic. Our study was too small to address all concerns about the toxicity of the higher dose rifabutin with LPV/r, most notably the decrease in neutrophil count, which requires further evaluation.

\section{Competing interests}

The authors declare that they have no competing interests.

\footnotetext{
Authors' contributions

SN, CC, HM, TR, AP carried out data analysis, SN, CC, HM, AH, CL, AP wrote the manuscript, $\mathrm{SN}, \mathrm{CL}, \mathrm{AH}, \mathrm{AP}$ managed and provided oversight of the clinical aspects of the study. AP, CL, HM conceived and designed the study. LW, TK, HM carried out the pharmacological analysis. All authors read and approved the final manuscript.
}

\section{Acknowledgements}

We wish to thank the following: Roxana Rustomjee for support in carrying out the study and to the patients and their families who participated in the study. We also like to thank the following for donation of study medications: Pfizer South Africa (Rifabutin), Aspen South Africa (Lamivudine, Stavudine), MSD South Africa (Efavirenz). We also acknowledge Devola Phillips who was the physician who cared for the patients during the study. The study was funded by ANRS (Agence Nationale de Recherche Sur le Sida et les Hépatites Virales). Open access publication of this article has been made possible through support from the Victor Daitz Information Gateway, an initiative of the Victor Daitz Foundation and the University of KwaZulu-Natal.

\section{Author details}

${ }^{1}$ TB Research Unit, Medical Research Council, Durban, South Africa. ${ }^{2}$ Biostatistics Unit, Medical Research Council, Durban, South Africa. ${ }^{3}$ Division of Clinical Pharmacology, Department of Medicine, University of Cape Town, Cape Town, South Africa. International Union Against Tuberculosis and Lung Disease, Paris, France. ${ }^{5}$ WHO STOP Tuberculosis Programme, Geneva, Switzerland. ${ }^{6} \mathrm{KwaZulu-Natal}$ Research Institute for Tuberculosis and HIV (K-RITH), University of KwaZulu-Natal, Durban, South Africa.

Received: 29 January 2014 Accepted: 22 October 2014 Published: 19 November 2014

\section{References}

1. World Health Organization, Global Tuberculosis report: WHO/HTM/TB/ 2014.08. 20 Avenue Appia, 1211 Geneva 27, Switzerland: WHO Press, World Health Organization; 2014.

2. Abdool Karim SS, Naidoo K, Grobler A, Padayatchi N, Baxter C, Gray A, Gengiah T, Nair G, Bamber S, Singh A, Khan M, Pienaar J, El-Sadr W, Friedland G, Abdool Karim Q: Timing of initiation of antiretroviral drugs during tuberculosis therapy. N Engl J Med 2010, 362:697-706.

3. Blanc FX, Sok T, Laureillard D, Borand L, Rekacewicz C, Nerrienet E, Madec Y, Marcy O, Chan S, Prak N, Kim C, Lak KK, Hak C, Dim B, Sin Cl, Sun S, Guillard B, Sar B, Vong S, Fernandez M, Fox L, Delfraissy JF, Goldfeld AE: Earlier versus later start of antiretroviral therapy in HIV-infected adults with tuberculosis. N Engl J Med 2011, 365:1471-1481.

4. Havlir DV, Kendall MA, Ive P, Kumwenda J, Swindells S, Qasba SS, Luetkemeyer AF, Hogg E, Rooney JF, Wu X, Hosseinipour MC, Lalloo U, Veloso VG, Some FF, Kumarasamy N, Padayatchi N, Santos BR, Reid S, Hakim J, Mohapi L, Mugyenyi P, Sanchez J, Lama JR, Pape JW, Sanchez A, Asmelash A, Moko E, Sawe F, Andersen J, Sanne I: Timing of antiretroviral therapy for HIV-1 infection and tuberculosis. N Engl J Med 2011, 365:1482-1491.

5. World Health Organization: Global HIV/AIDS response: epidemic update and health sector progress towards universal access. Progress report. 20 Avenue Appia, 1211 Geneva 27, Switzerland: WHO Press, World Health Organization; 2011.

6. Gupta RK, Jordan MR, Sultan BJ, Hill A, Davis DH, Gregson J, Sawyer AW, Hamers RL, Ndembi N, Pillay D, Bertagnolio S: Global trends in antiretroviral resistance in treatment-naive individuals with HIV after rollout of antiretroviral treatment in resource-limited settings: a global collaborative study and meta-regression analysis. Lancet 2012, 380:1250-1258.

7. Burman WJ, Gallicano K, Peloquin C: Comparative pharmacokinetics and pharmacodynamics of the rifamycin antibacterials. Clin Pharmacokinet 2001, 40:327-341.

8. Murphy RA, Marconi VC, Gandhi RT, Kuritzkes DR, Sunpath H: Coadministration of lopinavir/ritonavir and rifampicin in HIV and tuberculosis co-infected adults in South Africa. PLoS One 2012, 7:e44793.

9. Della Bruna C, Schioppacassi G, Ungheri D, Jabès D, Morvillo E, Sanfilippo A: LM 427, a new spiropiperidylrifamycin: in vitro and in vivo studies. J Antibiot 1983, 36:1502-1506.

10. Sanfilippo A, Della Bruna C, Marsili L, Morvillo E, Pasqualucci C, Schioppacassi G, Ungheri D: Biological activity of a new class of rifamycins. Spiro-piperidylrifamycins. J Antibiot 1980, 33:1193-1198.

11. Polk RE, Brophy DF, Israel DS, Patron R, Sadler BM, Chittick GE, Symonds WT, Lou Y, Kristoff D, Stein D: Pharmacokinetic Interaction between amprenavir and rifabutin or rifampin in healthy males. Antimicrob Agents Chemother 2001, 45:502-508.

12. CDC: Managing Drug Interactions in the Treatment of HIV-Related Tuberculosis. 1600 Clifton Rd., NE MS E10 Atlanta, GA 30333: Centers for Disease Control and Prevention, Division of Tuberculosis Elimination (DTBE); 2013. Available from URL: http://www.cdc.gov/tb/?404;http://www.cdc.gov:80/tb/TB_HIV_Drugs/default.htm. 
13. European AIDS Clinical Society: Guidelines version 7.02. Pierre - PL 709 Rue Haute 3221000 Brussels, Belgium: European AIDS Clinical Society (EACS) CHU; 2014. http://eacsociety.org/Portals/0/140601_EACS\%20EN7.02.pdf.

14. Moultrie H, Mcllleron H, Sawry S, Kellermann T, Wiesner L, Kindra G, Gous H, Van Rie A: Pharmacokinetics and safety of rifabutin in young HIV-infected children receiving rifabutin and lopinavir/ritonavir. J Antimicrobial Chemother 2014, doi:10.1093/jac/dku382 (Epub ahead of print).

15. Boulanger C, Hollender E, Farrell K, Stambaugh JJ, Maasen D, Ashkin D, Symes S, Espinoza LA, Rivero RO, Graham JJ, Peloquin CA: Pharmacokinetic evaluation of rifabutin in combination with lopinavir-ritonavir in patients with HIV infection and active tuberculosis. Clin Infect Dis: Off Publ Infect Dis Soc Am 2009, 49:1305-1311.

16. Khachi H, O'Connell R, Ladenheim D, Orkin C: Pharmacokinetic interactions between rifabutin and lopinavir/ritonavir in HIVinfected patients with mycobacterial co-infection. J Antimicrobial Chemother 2009, 64:871-873.

17. Jenny-Avital ER, Joseph K: Rifamycin-resistant Mycobacterium tuberculosis in the highly active antiretroviral therapy era: a report of 3 relapses with acquired rifampin resistance following alternate-day rifabutin and boosted protease inhibitor therapy. Clin Infect Dis 2009, 48:1471-1474.

18. Weiner M, Benator D, Burman W, Peloquin CA, Khan A, Vernon A, Jones B, Silva-Trigo C, Zhao Z, Hodge T: Association between acquired rifamycin resistance and the pharmacokinetics of rifabutin and isoniazid among patients with HIV and tuberculosis. Clin Infect Dis 2005, 40:1481-1491.

19. Ungheri D, Franceschi G, Dellaa Bruna C: Main Urinary metabolites of the spiropiperidyl rifamycin LM 427: isolation and biological properties. In Recent Advances in Chemotherapy. Edited by Ishigami J. Tokyo: Tokyo Press; 1986:1917-1918.

20. ACTG: AIDS Clinical Trials Group, Division of AIDS table for grading the severity of adult and pediatric adverse events. Rockville, MD: National Institutes of Health, National Institute of Allergy and Infectious Diseases, Division of AIDS; 2004.

21. Republic of South Africa Department of Health: South African National Tuberculosis Management Guidelines. Private Bag X828 Pretoria 0001 South Africa: Directorate of TB Control and Management; 2009.

22. Chi J, Jayewardene AL, Stone JA, Motoya T, Aweeka FT: Simultaneous determination of five HIV protease inhibitors nelfinavir, indinavir, ritonavir, saquinavir and amprenavir in human plasma by LC/MS/MS. J Pharm Biomed Anal 2002, 30:675-684.

23. La Porte C, Back D, Blaschke T, Boucher C, Fletcher C, Flexner C, Gerber J, Kashuba A, Schapiro J, Burger D: Updated guideline to perform therapeutic drug monitoring for antiretroviral agents. Rev Antivir Ther 2006, 3:4-14.

24. Davies G, Cerri S, Richeldi L: Rifabutin for treating pulmonary tuberculosis. Cochrane Database Syst Rev 2007, 4:1-21. doi:10.1002/14651858.CD005159.pub2.

25. Li J, Munsiff SS, Driver CR, Sackoff J: Relapse and acquired rifampin resistance in HIV-infected patients with tuberculosis treated with rifampin-or rifabutin-based regimens in New York City, 1997-2000. Clin Infect Dis 2005, 41:83-91.

26. Nettles RE, Mazo D, Alwood K, Gachuhi R, Maltas G, Wendel K, Cronin W, Hooper N, Bishai W, Sterling TR: Risk factors for relapse and acquired rifamycin resistance after directly observed tuberculosis treatment: a comparison by HIV serostatus and rifamycin use. Clin Infect Dis 2004, 38:731-736.

27. Spradling P, Drociuk D, McLaughlin S, Lee L, Peloquin C, Gallicano K, Pozsik C, Onorato I, Castro K, Ridzon R: Drug-drug interactions in inmates treated for human immunodeficiency virus and Mycobacterium tuberculosis infection or disease: an institutional tuberculosis outbreak. Clin Infect Dis 2002, 35:1106-1112.

28. Panel on Antiretroviral Guidelines for Adults and Adolescents: Guidelines for the use of antiretroviral agents in HIV-1-infected adults and adolescents. Section accessed Nov 2014, AIDSinfo P.O. Box 4780 Rockville, MD, USA: Department of Health and Human Services; Available at http://aidsinfo.nih. gov/contentfiles/lvguidelines/adultandadolescentgl.pdf.

29. Benator DA, Weiner MH, Burman WJ, Vernon AA, Zhao ZA, Khan AE, Jones BE, Sandman L, Engle M, Silva-Trigo C: Clinical Evaluation of the Nelfinavir-Rifabutin Interaction in Patients with Tuberculosis and Human Immunodeficiency Virus Infection. Pharmacother: J Human Pharmacol Drug Ther 2007, 27:793-800.

30. Hamzeh FM, Benson C, Gerber J, Currier J, McCrea J, Deutsch P, Ruan P, Wu $\mathrm{H}$, Lee J, Flexner C: Steady-state pharmacokinetic interaction of modifieddose indinavir and rifabutin*. Clin Pharmacol Ther 2003, 73:159-169.
31. Ford SL, Chen Y-C, Lou Y, Borland J, Min SS, Yuen GJ, Shelton MJ: Pharmacokinetic interaction between fosamprenavir-ritonavir and rifabutin in healthy subjects. Antimicrob Agents Chemother 2008, 52:534-538.

32. Sekar V, Lavreys L, Van de Casteele T, Berckmans C, Spinosa-Guzman S, Vangeneugden T, De Pauw M, Hoetelmans R: Pharmacokinetics of darunavir/ritonavir and rifabutin coadministered in HIV-negative healthy volunteers. Antimicrob Agents Chemother 2010, 54:4440-4445

33. Dooley KE, Sayre P, Borland J, Purdy E, Chen S, Song I, Peppercorn A, Everts S, Piscitelli S, Flexner C: Safety, tolerability, and pharmacokinetics of the HIV integrase inhibitor dolutegravir given twice daily with rifampin or once daily with rifabutin: results of a phase 1 study among healthy subjects. JAIDS J Acquir Immune Defic Syndr 2013, 62:21-27.

34. Colborn D, Lampiris H, Lee B, Lewis R, Sullam P, Narang PK: Concomitant cotrimoxazole (CTX) does not affect rifabutin (RBT) kinetics in HIV+ patients. Clin Pharmacol Therapuet 1996, 59:PI49-PI49.

35. Li RC, Nightingale S, Lewis RC, Colborn DC, Narang PK: Lack of effect of concomitant zidovudine on rifabutin kinetics in patients with AIDS-related complex. Antimicrob Agents Chemother 1996, 40:1397-1402.

36. Moyle G, Buss N, Goggin T, Snell P, Higgs C, Hawkins D: Interaction between saquinavir soft-gel and rifabutin in patients infected with HIV. Br J Clin Pharmacol 2002, 54:178-182.

37. Mitchison D, Dickinson JM: Laboratory aspects of intermittent drug therapy. Postgrad Med J 1971, 47:737.

38. Gumbo T, Louie A, Deziel MR, Liu W, Parsons LM, Salfinger M, Drusano GL: Concentration-dependent Mycobacterium tuberculosis killing and prevention of resistance by rifampin. Antimicrob Agents Chemother 2007, 51:3781-3788.

39. Jayaram R, Gaonkar S, Kaur P, Suresh B, Mahesh B, Jayashree R, Nandi V, Bharat S, Shandil R, Kantharaj E: Pharmacokinetics-pharmacodynamics of rifampin in an aerosol infection model of tuberculosis. Antimicrob Agents Chemother 2003, 47:2118-2124.

40. Diacon A, Patientia R, Venter A, Van Helden P, Smith P, Mcllleron H, Maritz J, Donald P: Early bactericidal activity of high-dose rifampin in patients with pulmonary tuberculosis evidenced by positive sputum smears. Antimicrob Agents Chemother 2007, 51:2994-2996.

41. Tanuma J, Sano K, Teruya K, Watanabe K, Aoki T, Honda H, Yazaki H, Tsukada K, Gatanaga H, Kikuchi Y, Oka S: Pharmacokinetics of rifabutin in Japanese HIV-infected patients with or without antiretroviral therapy. PLoS One 2013, 8:e70611.

42. Lan NT, Thu NT, Barrail-Tran A, Duc NH, Lan NN, Laureillard D, Lien TT, Borand L, Quillet C, Connolly C, Lagarde D, Pym A, Lienhardt C, Dung NH, Taburet AM, Harries AD: Randomised pharmacokinetic trial of rifabutin with lopinavir/ritonavir-antiretroviral therapy in patients with HIVassociated tuberculosis in Vietnam. PLoS One 2014, 9:e84866.

43. Apseloff G, Foulds G, LaBoy-Goral L, Kraut E, Vincent J: Severe neutropenia caused by recommended prophylactic doses of rifabutin. Lancet 1996, 348:685

44. Flexner C, Barditch-Crovo PA: Severe neutropenia among healthy volunteers given rifabutin in clinical trials*. Clin Pharmacol Ther 2003, 74:592-593.

45. Griffith DE, Brown BA, Girard WM, Wallace RJ: Adverse events associated with high-dose rifabutin in macrolide-containing regimens for the treatment of Mycobacterium avium complex lung disease. Clin Infect Dis 1995, 21:594-598.

46. Griffith DE, Brown BA, Wallace RJ: Varying dosages of rifabutin affect white blood cell and platelet counts in human immunodeficiency virus-negative patients who are receiving multidrug regimens for pulmonary Mycobacterium avium complex disease. Clin Infect Dis 1996, 23:1321-1322.

47. Shafran SD, Singer J, Zarowny DP, Deschênes J, Phillips P, Turgeon F, Aoki FY, Toma E, Miller M, Duperval R: Determinants of rifabutin-associated uveitis in patients treated with rifabutin, clarithromycin, and ethambutol for Mycobacterium avium complex bacteremia: a multivariate analysis. J Infect Dis 1998, 177:252-255.

48. Moh R, Danel C, Sorho S, Sauvageot D, Anzian A, Minga A, Gomis OB, Konga C, Inwoley A, Gabillard D: Haematological changes in adults receiving a zidovudine-containing HAART regimen in combination with co-trimoxazole in Côte d'Ivoire. Antivir Ther 2005, 10:615-624.

49. Kempf DJ, Marsh KC, Kumar G, Rodrigues AD, Denissen JF, McDonald E, Kukulka MJ, Hsu A, Granneman GR, Baroldi PA: Pharmacokinetic 
enhancement of inhibitors of the human immunodeficiency virus protease by coadministration with ritonavir. Antimicrob Agents Chemother 1997, 41:654-660.

50. Crommentuyn KM, Mulder JW, Mairuhu A, Van Gorp E, Meenhorst PL, Huitema A, Beijnen JH: The plasma and intracellular steady-state pharmacokinetics of lopinavir/ritonavir in HIV-1-infected patients. Antivir Ther 2004, 9:779-786.

doi:10.1186/2050-6511-15-61

Cite this article as: Naiker et al:: Randomized pharmacokinetic evaluation of different rifabutin doses in African HIV- infected tuberculosis patients on lopinavir/ritonavir-based antiretroviral therapy. BMC Pharmacology and Toxicology 2014 15:61.

\section{Submit your next manuscript to BioMed Central and take full advantage of:}

- Convenient online submission

- Thorough peer review

- No space constraints or color figure charges

- Immediate publication on acceptance

- Inclusion in PubMed, CAS, Scopus and Google Scholar

- Research which is freely available for redistribution 